\title{
Multilobed uveal melanoma masquerading as postoperative choroidal detachment*
}

\author{
JERRY A. SHIELDS, BRIAN C. LEONARD, AND LOV K. SARIN \\ From the Oncology Unit, Retina Service, Wills Eye Hospital and Research Institute, \\ Philadelphia, USA
}

It is well known that a choroidal detachment after intraocular surgery may clinically simulate a malignant melanoma of the uveal tract, and that such eyes have occasionally been enucleated with an erroneous diagnosis of malignant melanoma (Ferry, 1964; Shields and Zimmerman, 1973). The reverse situation, in which a malignant melanoma simulates a postoperative choroidal detachment, however, is extremely rare.

\section{Case report}

A 71-year-old myopic White woman was admitted to a local hospital because of dense cataracts in both eyes. Except for the lens opacities, which precluded a view of the fundi, her physical and ocular findings were reported to have been within normal limits. The patient underwent an uncomplicated cataract extraction in the left eye, followed one week later by a similar procedure in the right eye. At that time the left eye was noted to have a 'kissing choroidal detachment'. A retinal specialist agreed with the diagnosis and followed-up the patient conservatively for six weeks. Since the lesion failed to resolve the patient was referred to us for further evaluation to exclude the possibility of an intraocular tumour.

On examination the physical findings were normal except for mild hypertensive cardiovascular disease compatible with the patient's age. The positive findings were confined to the eyes. In the right eye the visual acuity was $6 / 24$ with pinhole. There was surgical aphakia with a sector surgical coloboma superiorly. Ophthalmoscopy showed moderately advanced myopic chorioretinopathy with a clear vitreous. In the left eye the visual acuity was perception of light without projection and the intraocular pressure was $10 \mathrm{mmHg}$ by applanation compared with $19 \mathrm{mmHg}$ in the right eye. There was no evidence of excessive episcleral pigmentation. Through the left pupil a trilobed dark-brown

*Presented at the 1975 Verhoeff Society Meeting, Washington, DC, 14 April 1975

Supported in part by the Retina Research and Development Foundation, Philadelphia, and the Lions Club of Pennsylvania

Address for reprints: Jerry A. Shields, Oncology Unit, Retina Service, Wills Eye Hospital, 160 I Spring Garden Street, Philadelphia, Pennsylvania I9130 mass was seen with the domes of the three lobes almost touching one another centrally. The inferotemporal lobe was displacing the ciliary processes centrally and the iris forward in that quadrant. Transillumination with a high-intensity fibre optics transilluminator showed no transmission of light through any of the lobes. B-scan ultrasonography showed a multilobed solid intraocular mass with a smooth surface and numerous internal reflections suggestive of either a tumour or haemorrhagic retinal detachment. Intravenous fluorescein angiography showed extensive leakage into the vitreous from the areas of detachment.

No definite diagnosis could be made. From the initial clinical studies the diagnosis was 'haemorrhagic choroidal detachment, rule out atypical malignant melanoma'. A transconjunctival (non-incisional) ${ }^{32} \mathrm{P}$ test was performed, comparing the inferotemporal mass with the symmetrical quadrant of the opposite eye. The procedure was performed with both the Detector Ocular Tumor Unit (EON Corporation) and the solid state semiconductor (Nuclear Associates, Technical Associates). The calculated percentage uptake was as follows :

$\begin{array}{ccc}\text { Post injection } & \text { EON unit } & \text { Solid state unit } \\ \text { I hour } & 143 & 145 \\ 24 \text { hours } & 176 & 179 \\ 48 \text { hours } & 205 & 230\end{array}$

This is considered a positive test (Hagler, Jarrett, and Humphrey, I970; Ruiz, 1972; Shields, Sarin, Federman, Mensheha-Manhart, and Carmichael, 1974; Shields, Hagler, Federman, Jarrett, and Carmichael, r 975a).

Because the lesion so closely resembled a choroidal detachment rather than a melanoma we thought that the ${ }^{32} \mathrm{P}$ results might represent a 'false positive'. We therefore did an incisional ${ }^{32} \mathrm{P}$ test immediately after the 48-hour transconjunctival test. This assured closer approximation of the probe to the lesion. Because it gave a positive result by the transconjunctival technique the dense inferotemporal mass was tested, the superonasal lobe in the same eye being used as a control area. The percentage uptakes of the lesion over the control were as follows:

$$
\begin{array}{cc}
\text { EON unit } & \text { Solid state unit } \\
56 \mathrm{I} & 448
\end{array}
$$

This was interpreted as an unequivocally positive test. Certain investigators have stated that a choroidal or subretinal haemorrhage can give a false-positive result 


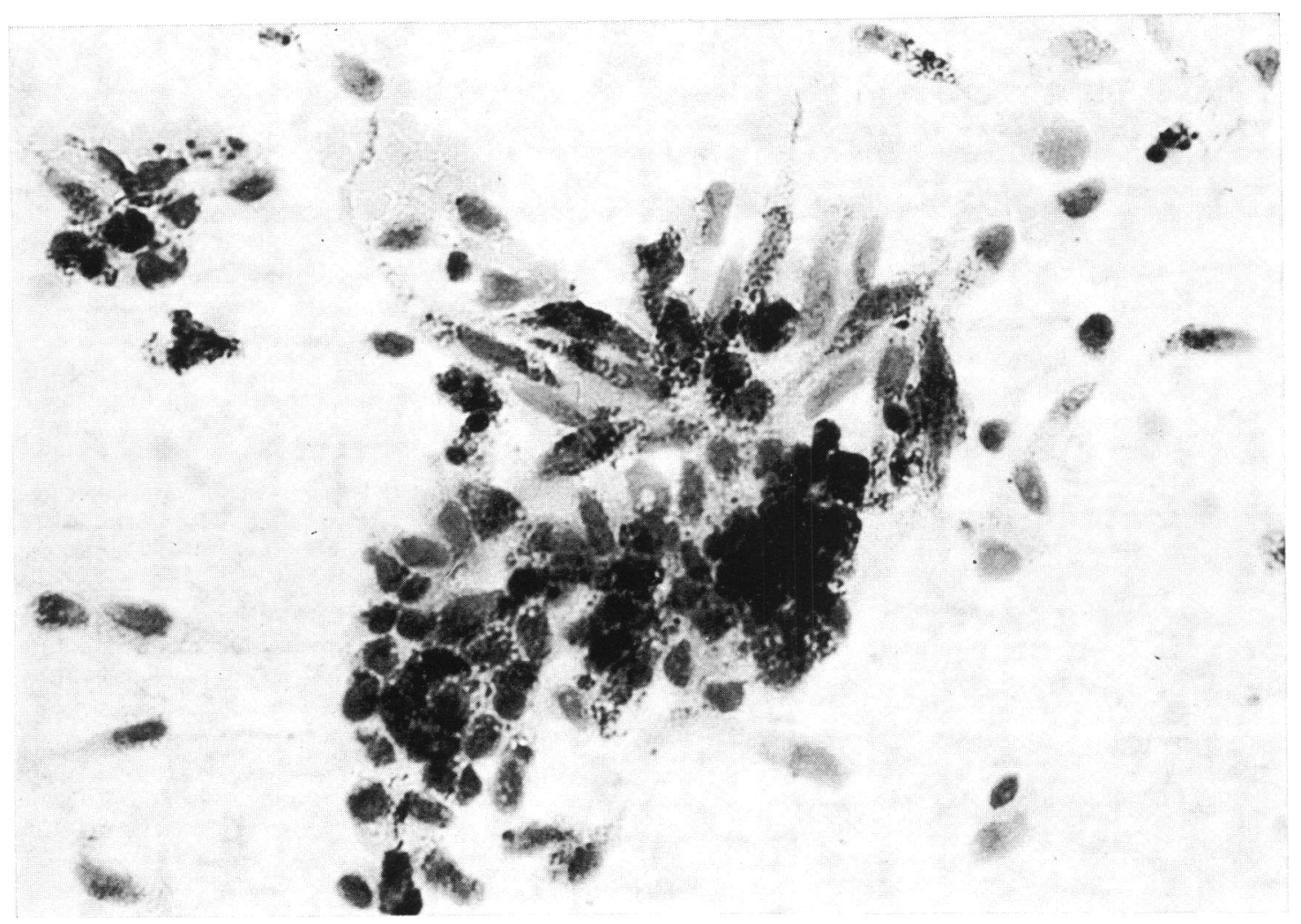

FIG. I Biopsy specimen showing spindle-shaped cells with pigment. Diagnosis: malignant melanoma, spindle-B cell type. Haematoxylin and eosin. $\times 640$

to the ${ }^{32} \mathrm{P}$ test. We therefore obtained tissue for biopsy from the inferotemporal mass through a trap-door pars plana incision. Several pieces of loose pigmented material were carefully removed and the wound was securely closed. Histological examination within 15 minutes showed numerous spindle-B malignant melanoma cells (Fig. I). The eye was subsequently enucleated.

\section{Pathology}

The globe measured $26 \times 26 \times 25 \mathrm{~mm}$ with $2 \mathrm{~mm}$ of optic nerve attached. There was a total retinal detachment with extensive haemorrhage and exudate in the subretinal space on the nasal side. On the temporal side the choroid was replaced by a large, multinodular pigmented tumour which filled almost one-half of the globe (Fig. 2).

Histologically the tumour consisted of predominantly spindle-B cells with occasional epithelioid cells (Callander classification). The biopsy site inferotemporally showed acute and chronic inflammatory cells superficially, but the tumour cells were confined within the globe. There was no evidence of extrascleral extension. Superiorly and nasally there was a total haemorrhagic and serous retinal detachment, which produced the dark elevations seen with the slit lamp.

\section{Discussion}

When a dark, multilobed mass is seen through the pupil of an eye with low intraocular pressure after cataract surgery the most likely diagnosis is a choroidal detachment. A serous choroidal detachment permits transillumination, whereas a dense haemorrhagic choroidal detachment, like a malignant melanoma, usually does not. This case had several features which were more suggestive of a haemorrhagic choroidal detachment than of a malignant melanoma.

A melanoma of the choroid or ciliary body is usually a solitary mass often associated with a serous detachment of the sensory retina. It is unusual for a melanoma to have a multilobed configuration or to produce an extensive haemorrhagic retinal detachment, as in this case. The haemorrhagic retinal detachment in the superior and nasal portions of the fundus produced dark, bullous masses which appeared identical clinically to the malignant melanoma in the inferotemporal fundus. Choroidal detachments after intraocular surgery are usually associated with low intraocular pressure. The pressure in the affected eye in this 
case was $10 \mathrm{mmHg}$ compared with $19 \mathrm{mmHg}$ in the other eye. This relative hypotony, however, does not exclude the diagnosis of malignant melanoma. In fact, we have found that most eyes with ciliary body melanomas which have not extensively invaded the anterior chamber angle have lower intraocular pressures than the fellow eye.

The ${ }^{32} \mathrm{P}$ test has recently enjoyed renewed popularity in American ophthalmology (Hagler and others, 1970; Ruiz, 1972; Shields and others, 1974, 1975a; Shields, Annesley, and Totino, 1975b; Shields, McDonald, Leonard, and Canny, r976c; Shields, Carmichael, Leonard, Federman, and Sarin, I976a; Shields, Carmichael, Leonard, Sarin, and Federman, 1976b). It may be a highly accurate diagnostic procedure in certain cases of atypical intraocular tumours (Shields and others. 1975a, 1975b; Shields and others, 1976c). We recently reported our results in 300 such procedures (Shields and others, 1976a, 1976b). With the transconjunctival (non-incisional) technique the incidence of false-positive results is less than $I$ per cent and the incidence of false-negative results about 4 per cent (Shields and others, 1976a). With the transcleral (incisional) technique there were no false-positive and an incidence of 2 per cent false-negative results (Shields and others, 1976b). We have found it the most accurate ancillary test for differentiating benign from malignant intraocular tumours. It was correct in predicting a malignancy in this case despite the clinical findings, which suggested a choroidal detachment rather than a melanoma. Because the transconjunctival (non-cutting) technique, which produced a positive result, may occasionally be misleading, we incised the conjunctiva for more precise localization. The percentage uptake of the inferotemporal mass over the superior mass (both of which appeared identical clinically) was 561 per cent with one standard counter and 448 per cent with another. Both of these were strongly positive, indicating that the inferotemporal mass was malignant.

Although it has not been our experience, some investigators have stated that false-positive ${ }^{32} \mathrm{P}$ test results may occur with haemorrhagic retinal and choroidal detachments. An intraocular biopsy, therefore, was performed to make certain that the lesion was a melanoma rather than a simulating lesion. We have used this technique successfully in certain difficult cases (Shields, Green, and McDonald, 1973). In this case biopsy confirmed the results of the ${ }^{32} \mathrm{P}$ test and the eye was subsequently enucleated. We do not recommend routine biopsy of suspected posterior uveal melanomas. In fact, biopsy may be contraindicated in such cases (Sanders, 1952; Makley, 1967; Sanders and Smith, 1972). With improved methods for diagnosing intraocular tumours (Shields and McDonald, 1974) biopsy should rarely be necessary.

An important aspect of this case is the diagnostic confusion that occurred. Perhaps the diagnostic difficulties could have been avoided if the patient had been investigated more thoroughly before the cataract extraction. Transillumination, if properly performed, would have shown a shadow corresponding to the tumour inferotemporally. Preoperative ultrasonography would also have detected the mass in this case. At present, however, this technique is often not readily available. As ultrasound becomes more widely used probably tumours will occasionally be detected in the preoperative evaluation of eyes with dense cataracts.

We recommend that visual acuity, transillumination, and ultrasonography findings are carefully evaluated in all patients with opaque cataracts. When a tumour pattern is found a ${ }^{32} \mathrm{P}$ test should be done to confirm or rule out a malignancy. Although the ${ }^{32} \mathrm{P}$ test, when properly performed, is highly accurate in diagnosing intraocular malignancies, therapeutic decisions should not be made solely on the findings. The evidence of ophthalmoscopy, transillumination, fluorescein angiography (Gass, 1974), ultrasonography, antibody studies (Federman, Lewis, Clark, Egerer, and Sarin, 1974), and other procedures must be taken 
into account before making a definitive therapeutic choice. With this approach, our diagnostic accuracy for intraocular tumours will continue to improve (Shields and McDonald, 1974).

\section{Summary}

A case of multilobed malignant melanoma with a haemorrhagic retinal detachment which mimicked a postoperative choroidal detachment is described. Because the lesion showed no resolution six weeks after cataract surgery a tumour evaluation was undertaken. The diagnosis was established with a positive radioactive phosphorus uptake $\left.{ }^{32} \mathrm{P}\right)$ test and biopsy of the intraocular mass. A suggested approach to the diagnosis in such difficult cases is proposed.

This patient was referred to the Oncology Unit by Dr Narendra Krishna, Coatesville, Pennsylvania. Dr Merlyn Rodrigues' performed the pathological examination, and Ms Thea Fischer reviewed the manuscript. Photographic assistance was provided by $\mathrm{Mr}$ Terrance L. Tomer and $\mathrm{Mr}$ Donald Morozin, and typing by Ms Jean Douglas.

\section{References}

federman, J. L., Lewis, M. G., Clark, w. h., JR., egerer, I., and Sarin, L. K. (1974) Trans. Amer. Acad.

Ophthal. Otolaryng., 78, 784

FERRY, A. P. (1964) Arch. Ophthal., 72, 463

GASS, J. D. M. (1974) 'Differential Diagnosis of Intraocular Tumors'. Mosby, St Louis

HAGLER, W. S., JARRETT, W. H. II, and hUMPhREY, w. T. (1970) Arch. Ophthal., 83, 548

MAKLEY, T. A. JR. (1967) Amer. J. Ophthal., 64, 591

RUIZ, R. D. (1972) Trans. Amer. Acad. Ophthal. Otolaryng., 76, 535

SANDERS, T. E. (1952) Trans. Amer. ophthal. Soc., 50, 375

- (1953) Amer. F. Ophthal., 36, 1204

, and SMITH, M. E. (1972) Int. Ophthal. Clin., 12, 163

ShieldS, J. A., ANNESley, w. H. JR., and totino, J. A. (1975b) Amer. F. Ophthal., 79, 634

-, CARMICHÁEL, P. L., LEONARD, B. C., FEDERMAN, J. L., and SARIN, L. K. (1976a) The accuracy of the ${ }^{32}$ P test for ocular melanomas. An analysis of 300 cases. I. Transconjunctival route. Presented at American Medical Association Section on Ophthalmology, Atlantic City, r6 June 1975

- - - SARIN, L. K., and FEDERMAN, J. L. (1976b) The accuracy of the ${ }^{32} \mathrm{P}$ test for ocular

melanomas. An analysis of 300 cases. II. Transcleral route. Presented at American Medical Association

Section on Ophthalmology, Atlantic City, 16 June 1975

, GREen, w. R., and MCDONALD, P. R. (1973) Arch. Ophthal., 89, 519

, hagler, w. S., feDerman, J. L., JaRrett, w. H. il, and Carmichael, p. l. (ig75a) Trams. Amer. Acad.

Ophthal. Otolaryng., 79, 297

SHiEldS, J. A., and MCDONALD, P. R. (1974) Arch. Ophthal., 9r, 259

- LeONARD, B. C., and CANNy, C. L. B. (1976c) Trans. Amer. ophthal. Soc. (in press)

-, SARIN, L. K., FEDERMAN, J. L., MEnSheha-MANHART, o., and CaRmichael, P. L. (1974) Ophthal. Surg., 5, I 3

, and zimmerman, L. E. (1973) Arch. Ophthal., 89, 466 